\title{
Low-density lipoprotein cholesterol levels are positively associated with the risk of endobronchial biopsy-induced refractory hemorrhage in patients with lung cancer
}

Saibin Wang ${ }^{1 *}$, Xianqing $\mathrm{Hu}^{2}$ and Yibin Pan $^{2^{*}}$

\begin{abstract}
Background: Lipoprotein concentrations have been associated with the major risk of bleeding events. However, whether plasma levels of LDL-C are associated with the risk of biopsy-related endobronchial hemorrhage remain elusive. Therefore, the present study was initiated to investigate the explicit association of low-density lipoprotein cholesterol (LDL-C) with endobronchial biopsy (EBB)-induced refractory hemorrhage in patients with lung cancer.

Methods: This retrospective study included a total of 659 consecutive patients with lung cancer who had undergone EBB at a tertiary hospital between January 2014 and April 2018. Using multiple regression analysis, the association between LDL-C and the risk of EBB-induced refractory hemorrhage was assessed after adjusting for potential confounding factors.
\end{abstract}

Results: A significant proportion $(13.8 \%, 91 / 659)$ of the patients experienced refractory hemorrhage following EBB. In multivariate regression analysis, higher plasma LDL-C concentrations were associated with increased risk of EBBinduced refractory hemorrhage in patients with lung cancer after adjusting for potential confounders $(P<0.05)$. Using the lowest quartile of plasma LDL-C as the reference group, the odds ratio (95\% confidence interval) of Q2, Q3, and Q4 were $2.32(1.07,5.03), 2.37(0.94,5.95)$, and $3.65(1.16,11.51)$, respectively $(P$ for trend $<0.05)$. Moreover, this association was noticeably more pronounced in male patients with lung cancer in the subgroup analysis $(P<$ 0.05).

Conclusions: Plasma LDL-C was positively correlated with the increased risk of EBB-induced refractory hemorrhage in patients with lung cancer; predominantly, the associated risk was more pronounced in male patients with lung cancer.

Keywords: Low-density lipoprotein cholesterol, Lung cancer, Bronchoscopy, Biopsy, Hemorrhage

\section{Background}

Endobronchial biopsy (EBB) via flexible bronchoscopy has emerged as a first-line minimally invasive transbronchial biopsy modality in the histopathologic diagnosis of pulmonary diseases [1]. Usually, the procedure has been proven to be safe; however, significant hemorrhage or

\footnotetext{
* Correspondence: saibinwang@hotmail.com; jhpyb@sina.com

'Department of Respiratory Medicine, Jinhua Municipal Central Hospital, Jinhua Hospital of Zhejiang University, No. 365, East Renmin Road, Jinhua 321000, Zhejiang Province, China

2Department of Cardiovascular Medicine, Jinhua Municipal Central Hospital, Jinhua Hospital of Zhejiang University, No. 365, East Renmin Road, Jinhua 321000, Zhejiang Province, China
}

refractory bleeding is frequently encountered by bronchoscopists. Moreover, massive biopsy-related endobronchial hemorrhage in the airway remains most difficult-tomanage complication and could be life-threatening due to difficult hemostasis following EBB [2, 3].

Lipoprotein concentrations have been associated with the risk of major bleeding in the brain and airways [4-6]. Low-density lipoprotein cholesterol (LDL-C) represents a well-established risk factor for cardiovascular disease [7] and has been documented to be associated with high risk of intracerebral hemorrhage $[8,9]$. However, whether plasma levels of LDL-C are associated with the risk of 
biopsy-related endobronchial hemorrhage remain elusive. As refractory bleeding during bronchoscopy remains extremely challenging and there are no definitive preoperative predictors reported, the present study hypothesized that LDL-C may be associated with biopsy-related endobronchial hemorrhage and may represent a potentially modifiable risk factor prior to EBB. Predominantly, patients with lung cancer are subjected to EBB, and malignant lesions were considered to be more susceptible to hemorrhage than benign mucosal lesions during EBB [10]. Herein, the present study was initiated to investigate the explicit relationship between plasma LDL-C and EBBinduced refractory hemorrhage in patients with lung cancer.

\section{Methods}

\section{Study design and subjects}

This retrospective cohort study included a total of 659 consecutive patients with lung cancer who underwent EBB at a large tertiary hospital (Jinhua Municipal Central Hospital, Jinhua, China) between January 2014 and April 2018. Patients' inclusion criteria were as follows: a. adult patients with endobronchial local exophytic lesions who had undergone EBB; b. histopathologically confirmed a diagnosis of primary lung cancer. The patients were excluded if presented any of the following risk factors, platelet count $<50 \times 10^{9} / \mathrm{L}$, coagulation dysfunction, bleeding tendencies, receiving continuous anti-platelet therapy or continuous anticoagulant therapy, presented with severe liver or kidney disease, heart failure, uncontrolled hypertension or pulmonary arterial hypertension, on mechanical ventilation, and on immunosuppressive status. Patients receiving antiplatelet drugs were asked to withhold medicines one week prior to bronchoscopy. For this study, refractory hemorrhage was defined as the EBB-induced hemorrhage with failed hemostasis requiring intrabronchial instillation of hemostatic drugs $\left(4{ }^{\circ} \mathrm{C}\right.$ physiological saline and diluted (1:10000) adrenalin), and thus additional hemostatic measures (argon plasma coagulation (APC), electrocoagulation, vasopressin or hemocoagulase) were requisite for hemostasis [11]. Patients were classified into the EBB-induced refractory hemorrhage group and the non-refractory hemorrhage group based on hemostatic measures applied following EBB. This study complies with the Declaration of Helsinki and was approved by the ethics committee of Jinhua Municipal Central Hospital. Informed consent was waived because the data used in this study were anonymous.

\section{Variables collection}

The following clinicopathological characteristics of patients were retrieved from the electronic medical record, including gender, age, smoking history, weight, systolic blood pressure (SBP), diastolic blood pressure, location of the lesion, histological type, and stage of cancer. Data on patient's comorbidities including hypertension, chronic obstructive pulmonary disease (COPD), coronary heart disease (CHD), and diabetes mellitus were also collected. Laboratory investigations data including LDLC, high-density lipoprotein cholesterol (HDL-C), total cholesterol, triglyceride, apolipoprotein $\mathrm{B}$, apolipoprotein E, platelet counts, white blood cell counts, neutrophil percentage, hemoglobin, prothrombin time (PT), activated partial thromboplastin time (APTT), C-reactive protein (CRP), aspartate aminotransferase, and alanine aminotransferase (ALT) were also recorded. Blood laboratory investigations were performed on the first visit or admission, three days prior to EBB.

\section{EBB procedures}

All bronchoscopic and EBB procedures were performed by two experienced bronchoscopists. The procedures followed were as described previously [11]. Three to five biopsies were collected from the same endobronchial exophytic lesion using rigid endoscopic biopsy forceps [12]; however, when the lesion bled significantly following the first biopsy, only one biopsy was conducted. In this study, EBB-induced hemorrhage was self-limiting or hemostasis achieved using hemostatic drugs, including intrabronchial instillation of cold physiological saline $\left(4{ }^{\circ} \mathrm{C}\right)$ and/or diluted adrenalin, intravenous injection of vasopressin and/or hemocoagulase, electrocoagulation, and APC.

\section{Statistical analysis}

Descriptive statistics were used to summarize clinicopathological characteristics. Categorical variables are expressed as the number (percentage) and continuous variables as the median (interquartile). Unpaired $t$-tests or Mann-Whitney U test, Pearson chi-squared tests or the Fisher's exact, were used for the comparison between the two groups, as appropriate. The correlation between LDL-C level and the risk of EBB-induced refractory hemorrhage was examined using the smoothing curve fitting via a generalized additive model. Multivariate regression analysis was performed to evaluate the independent effects of LDL-C on the risk of EBB-induced refractory hemorrhage with or without adjustment for potential confounders. Two criteria for adjusting potential confounders were applied in this study: (1) model I: variables that needed to be adjusted by clinical significance [5, 6, 13]; (2) model II: in covariant-discrimination algorithm, variables included producing a change $\geq 10 \%$ of the regression coefficient after introduction into the basic model or removing from the complete model; and the regression coefficient of co-variable to dependent variable yielded $P$-value $<0.05$. All analyses were 
Table 1 Baseline characteristics of the study participants

\begin{tabular}{|c|c|c|c|}
\hline \multirow[t]{2}{*}{ Variables } & \multicolumn{2}{|c|}{ EBB-induced refractory hemorrhage } & \multirow[t]{2}{*}{$P$-value } \\
\hline & Yes $(n=91)$ & No $(n=568)$ & \\
\hline Gender, $n(\%)$ & & & 0.305 \\
\hline Female & $16(17.6)$ & $127(22.4)$ & \\
\hline Male & $75(82.4)$ & $441(77.6)$ & \\
\hline Age (year), median (Q1-Q3) & $65(59-72)$ & $65(59-70)$ & 0.561 \\
\hline Weight (kg), median (Q1-Q3) & $59.5(53.0-65.2)$ & $59.0(53.0-66.0)$ & 0.794 \\
\hline Smoking, n (\%) & & & 0.027 \\
\hline No & $24(26.4)$ & $218(38.4)$ & \\
\hline Yes & $67(73.6)$ & $350(61.6)$ & \\
\hline SBP (mmHg), median (Q1-Q3) & $129(112-144)$ & $131(119-145)$ & 0.285 \\
\hline DBP (mmHg), median (Q1-Q3) & $79.0(71-88)$ & $78.0(70-87)$ & 0.361 \\
\hline \multicolumn{4}{|l|}{ Coexisting Disease } \\
\hline COPD, $n(\%)$ & & & 0.826 \\
\hline No & $84(92.3)$ & $528(93.0)$ & \\
\hline Yes & $7(7.7)$ & $40(7.0)$ & \\
\hline Hypertension, n (\%) & & & 0.140 \\
\hline No & $63(69.2)$ & $434(76.4)$ & \\
\hline Yes & $28(30.8)$ & $134(23.6)$ & \\
\hline Diabetes mellitus, $n(\%)$ & & & 0.294 \\
\hline No & $89(97.8)$ & $538(94.7)$ & \\
\hline Yes & $2(2.2)$ & $30(5.3)$ & \\
\hline CHD, n (\%) & & & 1.000 \\
\hline No & $88(96.7)$ & $548(96.5)$ & \\
\hline Yes & $3(3.3)$ & $20(3.5)$ & \\
\hline \multicolumn{4}{|l|}{ Tumor Characteristics } \\
\hline Location of the lesion, $n$ (\%) & & & 0.045 \\
\hline Central airways & $20(22.0)$ & 79 (13.9) & \\
\hline Peripheral bronchi & $71(78.0)$ & $489(86.1)$ & \\
\hline Stage of cancer, $n(\%)$ & & & 0.461 \\
\hline Early & $52(57.1)$ & $301(53.0)$ & \\
\hline Advanced & $39(42.9)$ & $267(47.0)$ & \\
\hline Histological types, $n(\%)$ & & & $<0.001$ \\
\hline Adenocarcinoma & $11(12.1)$ & $165(29.0)$ & \\
\hline Squamous cell carcinoma & $63(69.2)$ & $268(47.2)$ & \\
\hline SCLC & $13(14.3)$ & $103(18.1)$ & \\
\hline Other ${ }^{a}$ & $4(4.4)$ & $32(5.6)$ & \\
\hline \multicolumn{4}{|l|}{ Laboratory Tests, median (Q1-Q3) } \\
\hline WBC $\left(\times 10^{9} / \mathrm{L}\right)$ & $6.8(5.5-8.9)$ & $6.8(5.5-8.6)$ & 0.977 \\
\hline Neutrophils (\%) & $72.2(64.2-80.4)$ & $69.5(61.9-76.1)$ & 0.025 \\
\hline Hemoglobin (g/L) & $126(116-137)$ & $128(116-140)$ & 0.325 \\
\hline platelets $\left(\times 10^{9} / \mathrm{L}\right)$ & $237(167-296)$ & $225(174.0-284)$ & 0.687 \\
\hline CRP (mg/L) & $12.7(3.0-37.7)$ & $5.9(1.1-28.9)$ & 0.009 \\
\hline PT (S) & $13.2(12.3-13.6)$ & $12.6(11.7-13.3)$ & $<0.001$ \\
\hline APTT (S) & $36.1(33.0-40.0)$ & $34.0(31.5-37.1)$ & $<0.001$ \\
\hline ALT (IU/L) & $14.0(11.5-21.3)$ & $17.0(12.0-26.0)$ & 0.027 \\
\hline AST (IU/L) & $22.6(18.0-27.1)$ & $23.0(19.0-29.0)$ & 0.289 \\
\hline
\end{tabular}


Table 1 Baseline characteristics of the study participants (Continued)

\begin{tabular}{|c|c|c|c|}
\hline \multirow[t]{2}{*}{ Variables } & \multicolumn{2}{|c|}{ EBB-induced refractory hemorrhage } & \multirow[t]{2}{*}{$P$-value } \\
\hline & Yes $(n=91)$ & No $(n=568)$ & \\
\hline Triglyceride (mmol/L) & $1.0(0.8-1.4)$ & $1.1(0.8-1.5)$ & 0.793 \\
\hline TC $(\mathrm{mmol} / \mathrm{L})$ & $4.1(3.6-4.7)$ & $4.1(3.5-4.8)$ & 0.663 \\
\hline $\mathrm{HDL}-\mathrm{C}(\mathrm{mmol} / \mathrm{L})$ & $1.1(0.9-1.2)$ & $1.1(0.9-1.3)$ & 0.069 \\
\hline LDL-C (mmol/L) & $2.9(2.4-3.4)$ & $2.7(2.2-3.3)$ & 0.143 \\
\hline Apolipoprotein B (g/L) & $1.0(0.8-1.2)$ & $1.0(0.8-1.2)$ & 0.569 \\
\hline Apolipoprotein E (mg/dL) & $3.3(2.5-4.4)$ & $3.6(2.8-4.7)$ & 0.078 \\
\hline
\end{tabular}

a "Other" includes histological type of NSCLC (not specified, $n=12$ ), neuroendocrine carcinoma ( $n=7$ ), adenosquamous carcinoma ( $n=5$ ), mucoepidermoid carcinoma $(n=2)$, adenoid cystic carcinoma $(n=1)$, carcinosarcoma $(n=1)$ and lung cancer without histological type specified $(n=8)$. EBB, endobronchial biopsy, SBP, systolic blood pressure, DBP, diastolic blood pressure, COPD, chronic obstructive pulmonary disease, CHD, coronary heart disease, SCLC, small-cell lung carcinoma, WBC, white blood cell, CRP, C-reactive protein, PT, prothrombin time, APTT, activated partial thromboplastin time, ALT, alanine aminotransferase, AST, aspartate aminotransferase, TC, total cholesterol, HDL-C, high-density lipoprotein cholesterol, LDL-C, lowdensity lipoprotein cholesterol

performed using R software (version 3.5.3), and P-value $<0.05$ was considered statistically significant.

\section{Results}

The clinicopathological characteristics and laboratory investigation of the patients were summarized in Table 1 . A total of 91 (13.8\%) of the patients with lung cancer experienced refractory bleeding following EBB; however, no case of death due to severe bleeding was recorded. The median levels of plasma LDL-C of all the subjects were $2.8 \mathrm{mmol} / \mathrm{L}$. There was no significant difference in the levels of plasma LDL-C between the refractory hemorrhage group and the non-refractory hemorrhage group $(P>0.05$, Table 1$)$. Location of the lesion, histological type (Fig. 1), neutrophil percentage, CRP, PT, APTT, and ALT correlated with EBB-induced refractory bleeding as assessed by univariate analysis $(P<0.05$, Table 1).

Smoothing curve fitting showed a significant correlation between plasma levels of LDL-C and the risk of EBB-induced refractory hemorrhage (Fig. 2). Increased risk of bleeding with increasing levels of LDL-C was observed in multivariate regression analyses after adjusting for the potential confounders either in the model I (adjusted for location of the lesion, histological type, stage, HDL-C, and apolipoprotein E) or in model II (adjusted for gender, location of the lesion, histological type, smoking, SBP, hemoglobin, neutrophil percentage, PT,
APTT, CRP, ALT, triglyceride, HDL-C, apolipoprotein $\mathrm{B}$, and apolipoprotein E) (Table 2). Furthermore, using the lowest quartile of plasma LDL-C as the reference group, the odds ratio (95\% confidence interval [CI]) of Q2, Q3, and Q4 were 2.32 (1.07, 5.03), $2.37(0.94,5.95)$, and $3.65(1.16,11.51)$ ( $P$ for trend $<0.05$, Table 2$)$.

In subgroup analyses, a significant association was observed for gender $(P$ for interaction $=0.0256$, Table 3 ); however, there was no statistical significance observed for smoking, coexisting diseases (hypertension, diabetes mellitus, CHD, and COPD), location of the lesion, stage of cancer, and histological type ( $P$ for interaction $>0.05$ ). These results indicated that there was a significant association between gender of patients and plasma LDL-C. Precisely, the effect of LDL-C on the risk of EBBinduced refractory hemorrhage in patients with lung cancer exhibited a significant difference between the two genders. Significantly higher plasma levels of LDL-C were observed in male patients $(\beta=3.81$ (95\% CI: 1.88 , 7.72)) with EBB-induced refractory hemorrhage than female patients ( $\beta=0.60$ (95\% CI: 0.12, 2.91)).

\section{Discussion}

The present study investigated levels of plasma LDL-C in patients with endobronchial local exophytic lesions who underwent $\mathrm{EBB}$ for its possible relationship with EBB-induced refractory hemorrhage in patients with lung cancer. The results indicated that levels of plasma
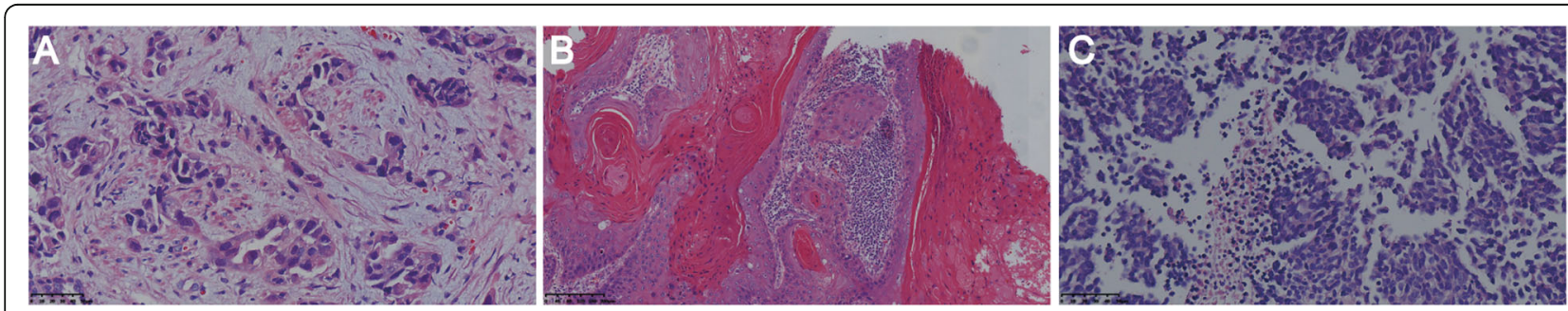

Fig. 1 Microscopic appearance (H\&E). Histological types of lung adenocarcinoma $(\mathbf{a}, \times 400)$, lung squamous cell carcinoma $(\mathbf{b}, \times 100)$, and smallcell lung carcinoma $(\mathbf{c}, \times 400)$ 


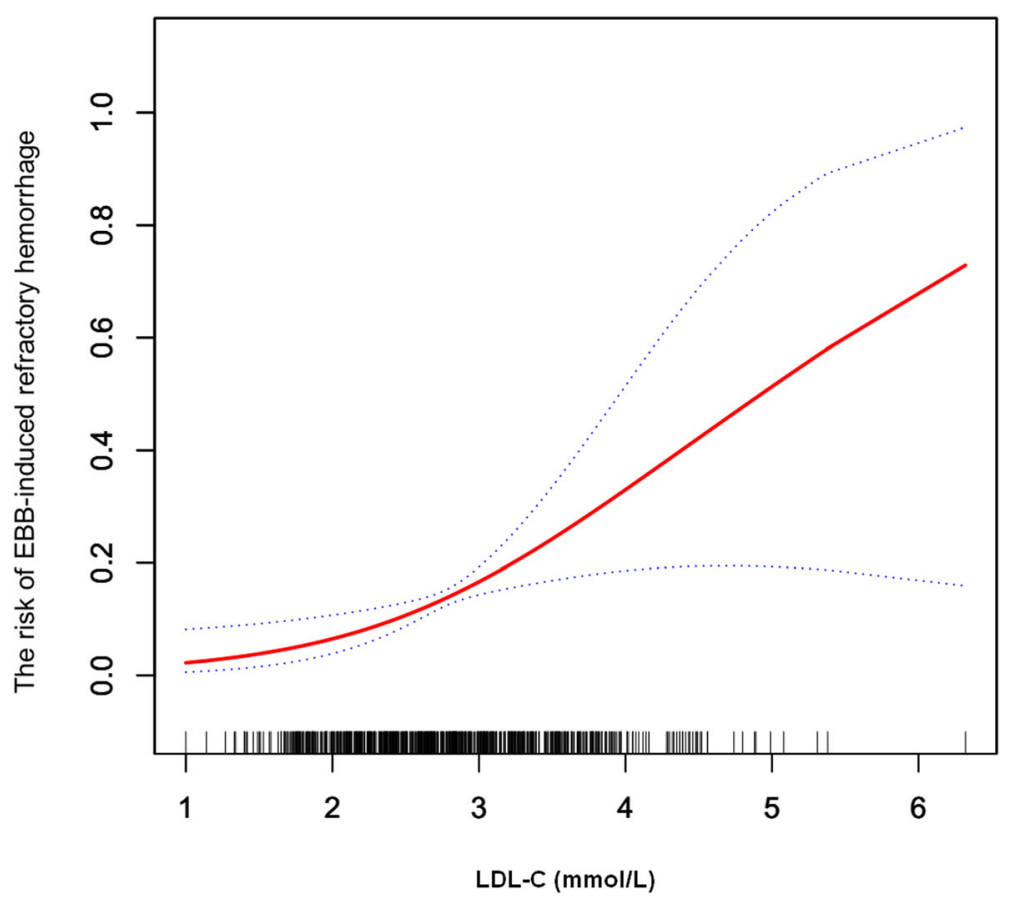

Fig. 2 The smooth curve fitting shows the association between plasma LDL-C and the risk of EBB-induced refractory hemorrhage after adjusting for the main confounders (gender, location of the lesion, histological type, smoking, SBP, hemoglobin, neutrophil percentage, PT, APTT, CRP, ALT, triglyceride, $\mathrm{HDL}-\mathrm{C}$, apolipoprotein B, and apolipoprotein E). Dotted lines represented the upper and lower 95\% confidence intervals. LDL-C, lowdensity lipoprotein cholesterol; EBB endobronchial biopsy; SBP, systolic blood pressure; PT, prothrombin time; APTT, activated partial thromboplastin time; CRP, C-reactive protein; ALT, alanine aminotransferase; HDL-C, high-density lipoprotein cholesterol

LDL-C were positively correlated with EBB-induced refractory hemorrhage in patients with lung cancer. Furthermore, there was a significant association between gender of patients with lung cancer and levels of plasma LDL-C, implying that male patients with lung cancer had a significantly higher risk of refractory bleeding than female patients following EBB.

EBB-induced hemorrhage is the most frequent and difficult-to-manage complication encountered during bronchoscopy, particularly when performing biopsies in patients with lung cancer. Conceivably, endobronchial refractory bleeding or massive hemorrhage in the airway may be life-threatening $[2,3]$. Several factors have been associated with the risk of bleeding during bronchoscopy, including immunosuppressive status, thrombocytopenia (platelet count $<50 \times 10^{9} / \mathrm{L}$ ), uncontrolled hypertension or pulmonary arterial hypertension, lung transplant, anticoagulant and/or antiplatelet drug use, severe liver and/or kidney disease, and bleeding tendencies [6, 13-16]. In recent years, accumulating evidence has suggested that high concentrations of lipoprotein(a) have been associated with low risk of major bleeding episodes in the brain and airways [4]. With regard to intra-airway intervention-related bleeding, HDL-C and apolipoprotein-E were noticeably

Table 2 Multivariate regression analysis of LDL-C and the risk of EBB-induced refractory hemorrhage

\begin{tabular}{clll}
\hline Parameter & Crude OR $(95 \% \mathrm{Cl}) p$-value & Model I OR $(95 \% \mathrm{Cl}) p$-value & Model II OR (95\% Cl) $p$-value \\
\hline $\begin{array}{l}\text { LDL-C }(\mathrm{mmol} / \mathrm{L}) \\
\text { Quartile of LDL-C }(\mathrm{mmol} / \mathrm{L})\end{array}$ & $1.24(0.93,1.65) 0.1437$ & $1.48(1.08,2.02) 0.0142$ & $2.65(1.40,5.00) 0.0026$ \\
Q1 $(<2.26)$ & Ref. & Ref. & Ref. \\
Q2 $(2.26-2.75)$ & $1.81(0.93,3.55) 0.0830$ & $2.01(1.01,4.01) 0.0465$ & $2.32(1.07,5.03) 0.0327$ \\
Q3 $(2.76-3.28)$ & $1.57(0.78,3.13) 0.2031$ & $1.82(0.89,3.71) 0.1011$ & $2.37(0.94,5.95) 0.0665$ \\
Q4 (>3.28) & $1.73(0.88,3.41) 0.1110$ & $2.48(1.21,5.07) 0.0128$ & $3.65(1.16,11.51) 0.0270$ \\
P for trend & 0.2013 & 0.0259 & 0.0464
\end{tabular}

Model I adjusts for location of the lesion, histological types, stage of cancer, HDL-C, and apolipoprotein E. Model II adjusts for gender, location of the lesion, histological type, smoking, SBP, hemoglobin, neutrophil percentage, PT, APTT, CRP, ALT, triglyceride, HDL-C, apolipoprotein B, and apolipoprotein E. LDL-C, lowdensity lipoprotein cholesterol; EBB endobronchial biopsy; SBP, systolic blood pressure; PT, prothrombin time; APTT, activated partial thromboplastin time; CRP, Creactive protein; ALT, alanine aminotransferase; HDL-C, high-density lipoprotein cholesterol 
Table 3 Effect of LDL-C on EBB-induced refractory hemorrhage in subgroups

\begin{tabular}{|c|c|c|c|}
\hline Characteristic & Number of patients & $\beta(95 \% \mathrm{Cl})$ & P for interaction \\
\hline Gender & & & 0.0256 \\
\hline Female & 143 & $0.60(0.12,2.91)$ & \\
\hline Male & 516 & $3.81(1.88,7.72)$ & \\
\hline Smoking & & & 0.6460 \\
\hline Yes & 242 & $2.86(1.38,5.96)$ & \\
\hline No & 417 & $2.12(0.68,6.60)$ & \\
\hline Hypertension & & & 0.8006 \\
\hline Yes & 162 & $2.46(1.08,5.60)$ & \\
\hline No & 497 & $2.68(1.39,5.19)$ & \\
\hline Diabetes mellitus & & & 0.9991 \\
\hline Yes & 32 & $0.00(0.00$, inf $)$ & \\
\hline No & 627 & $2.75(1.44,5.27)$ & \\
\hline $\mathrm{CHD}$ & & & 0.9994 \\
\hline Yes & 23 & $\inf .(0.00$, inf $)$ & \\
\hline No & 636 & $2.59(1.33,5.05)$ & \\
\hline COPD & & & 0.5498 \\
\hline Yes & 612 & $5.73(0.41,79.26)$ & \\
\hline No & 47 & $2.65(1.36,5.14)$ & \\
\hline Location of the lesion & & & 0.6326 \\
\hline Peripheral bronchi & 560 & $2.65(1.31,5.35)$ & \\
\hline Central airway & 99 & $3.84(0.94,15.58)$ & \\
\hline Stage & & & 0.7970 \\
\hline Early & 353 & $2.76(1.27,5.99)$ & \\
\hline Advanced & 306 & $2.38(0.93,6.10)$ & \\
\hline Histological type & & & 0.1136 \\
\hline Adenocarcinoma & 176 & $0.37(0.05,2.48)$ & \\
\hline Squamous cell carcinoma & 331 & $4.61(1.98,10.71)$ & \\
\hline SCLC & 116 & $2.85(0.48,16.94)$ & \\
\hline Other ${ }^{a}$ & 36 & $\inf .(0.00$, inf) & \\
\hline
\end{tabular}

Adjusted for gender, location of the lesion, histological type, smoking, SBP, hemoglobin, neutrophil percentage, PT, APTT, CRP, ALT, triglyceride, HDL-C, apolipoprotein B, and apolipoprotein E; in each case, the model was not adjusted for the stratification variable. "a "Other" includes histological types of NSCLC (not specified, $n=12)$, neuroendocrine carcinoma $(n=7)$, adenosquamous carcinoma $(n=5)$, muco-epidermoid carcinoma $(n=2)$, adenoid cystic carcinoma ( $n=1)$, carcinosarcoma $(n=1)$ and lung cancer without histological type specified $(n=8)$. LDL-C, low-density lipoprotein cholesterol; EBB endobronchial biopsy; CHD, coronary heart disease; COPD, chronic obstructive pulmonary disease; NSCLC, non-small cell lung carcinoma; SBP, systolic blood pressure; PT, prothrombin time; APTT, activated partial thromboplastin time; CRP, C-reactive protein; ALT, alanine aminotransferase; HDL-C, high-density lipoprotein cholesterol

associated with the risk of EBB-induced bleeding in a non-linear pattern $[5,6]$. Consistently, this study found that elevated LDL-C level was correlated with increased risk of EBB-induced refractory hemorrhage. Moreover, this association between the two did not lose its significance even after strict statistical adjustments for potential confounders. Although the exact mechanism underlying this association remains undetermined, it may be mediated partially through the regulation of adiponectin, an adipose-derived cytokine, which has been reported to exhibit an effect on platelet hyperactivity, hypercoagulability, and hypofibrinolysis [17-19]. Apparently, there was an inverse relationship between blood adiponectin and LDL$C$ [20], and LDL-C could alter DNA methylation levels of adiponectin both in adipose tissues and blood cells [21].

Furthermore, in this study, we performed subgroup analyses and interaction tests. An interaction effect was observed between gender and LDL-C, which indicated that LDL-C levels had a greater impact on male patients with lung cancer and caused refractory hemorrhage following EBB than on female patients. This finding might help recognize patients at increased risk of developing hemorrhage in a preoperative individualized assessment of bleeding risk, and provide evidence for gender-related 
differences in LDL-C management in patients with lung cancer [22].

Several limitations of the present study are worth noting. Firstly, this was a single-center retrospective study. Although we performed stringent statistical adjustments to minimize residual confounding factors, the study inevitably suffered from confounders and selection bias. Moreover, subjects included in this study were divided into the refractory bleeding group or non-refractory bleeding group based on hemostasis measures they received following EBB, and thus this classification might have introduced biases arising from an inaccurate grouping of some patients. Secondly, in patients with refractory hemorrhage, there was a high probability of difference in the amount of bleeding; however, we could not provide a quantitative measurement of blood loss. Besides, it remains challenging to accurately quantify blood loss during bronchoscopy [23]. Despite the aforementioned limitations, this study was the first to reveal the explicit relationship between plasma LDL-C and the risk of EBB-induced refractory hemorrhage in patients with lung cancer.

\section{Conclusions}

In conclusion, the findings of the present study indicated a positive correlation of plasma LDL-C with the increased risk of EBB-induced refractory bleeding in patients with lung cancer, and this associated risk was more pronounced in male patients. Furthermore, this finding might assist clinicians in recognizing patients with increased risk of EBB-induced hemorrhage prior to bronchoscopy for their possible improved management during EBB.

\section{Abbreviations}

ALT: Alanine aminotransferase; APC: Argon plasma coagulation; APTT: Activated partial thromboplastin time; CHD: Coronary heart disease; Cl: Confidence interval; COPD: Chronic obstructive pulmonary disease: CRP: C-reactive protein; EBB: Endobronchial biopsy; HDL-C: High-density lipoprotein cholesterol; LDL-C: Low-density lipoprotein cholesterol; PT: Prothrombin time

\section{Acknowledgements}

We appreciate the help and support of all the participants involved in the study. We gratefully thank Dr. Lixia Wang (Department of Pathology, Jinhua Municipal Central Hospital, China) for excellent technical assistance.

\section{Authors' contributions}

SW. contributed substantially to the study design, data analysis and interpretation, the writing of the manuscript, and takes responsibility for the integrity of the data and the accuracy of the data analysis. XH. and YP. contributed to data collection, data analysis, data interpretation, and manuscript revision. All authors read and approved the final manuscript.

\section{Funding}

This study was supported by the Medical and Health Science and Technology Plan Project of Zhejiang Province (No. 2018 RC079 to S. W.), the Science and Technology Project of Zhejiang Province (No. 2017 C37147 to S. W.), the Science and Technology Key Project of Jinhua City (No. 20163011 to S. W.), and the Science and Technology Project of Jinhua City (No. 20164024 to Y.P.)

\section{Availability of data and materials}

The datasets used and/or analyzed during the current study are available from the corresponding author on reasonable request.

Ethics approval and consent to participate

This study was approved by the ethics committee of Jinhua Municipal Central Hospital. The requirement for informed consent was waived because the data were handled anonymously.

\section{Consent for publication}

Not applicable.

\section{Competing interests}

The authors declare that they have no competing interests.

Received: 29 May 2019 Accepted: 23 October 2019

Published online: 04 November 2019

\section{References}

1. Fallon J, Medford ARL. Endobronchial and transbronchial biopsy experience: a United Kingdom survey. Thorac Cancer. 2017;8:291-5.

2. Bernasconi M, Koegelenberg CFN, Koutsokera A, Ogna A, Casutt A, Nicod L, Lovis A. latrogenic bleeding during flexible bronchoscopy: risk factors, prophylactic measures and management. ERJ Open Res. 2017;3. https://doi. org/10.1183/23120541.00084-2016.

3. Abuqayyas S, Raju S, Bartholomew JR, Abu Hweij R, Mehta AC. Management of antithrombotic agents in patients undergoing flexible bronchoscopy. Eur Respir Rev. 2017;26. https://doi.org/10.1183/16000617.0001-2017.

4. Langsted A, Kamstrup PR, Nordestgaard BG. High lipoprotein(a) and low risk of major bleeding in brain and airways in the general population: a mendelian randomization study. Clin Chem. 2017;63:1714-23.

5. Wang S, Zhang J, Lu X. Non-linear association of plasma level of highdensity lipoprotein cholesterol with endobronchial biopsy bleeding in patients with lung cancer. Lipids Health Dis. 2019;18:17.

6. Wang S, Ye Q, Lu X. Plasma apolipoprotein E level is associated with the risk of endobronchial biopsy-induced bleeding in patients with lung cancer. Lipids Health Dis. 2018;17:166.

7. Silverman MG, Ference BA, Im K, Wiviott SD, Giugliano RP, Grundy SM, Braunwald E, Sabatine MS. Association between lowering LDL-C and cardiovascular risk reduction among different therapeutic interventions: a systematic review and meta-analysis. JAMA. 2016;316:1289-97.

8. Sun L, Clarke R, Bennett D, Guo Y, Walters RG, Hill M, Parish S, Millwood IY, Bian Z, Chen Y, et al. Causal associations of blood lipids with risk of ischemic stroke and intracerebral hemorrhage in Chinese adults. Nat Med. 2019;25:569-74.

9. Chang JJ, Katsanos AH, Khorchid Y, Dillard K, Kerro A, Burgess LG, Goyal N, Alexandrov AW, Alexandrov AV, Tsivgoulis G. Higher low-density lipoprotein cholesterol levels are associated with decreased mortality in patients with intracerebral hemorrhage. Atherosclerosis. 2018;269:14-20.

10. Ozgül MA, Turna A, Yildiz P, Ertan E, Kahraman S, Yilmaz V. Risk factors and recurrence patterns in 203 patients with hemoptysis. Tuberk Toraks. 2006;54: 243-8.

11. Wang S. Development of a predictive model of difficult hemostasis following endobronchial biopsy in lung cancer patients. Biomed Res Int. 2019;2019:1656890.

12. Rivera MP, Mehta AC, Wahidi MM. Establishing the diagnosis of lung cancer: diagnosis and management of lung cancer, 3rd ed: American College of Chest Physicians evidence-based clinical practice guidelines. Chest. 2013; 143:e142S-65S.

13. Wang $S$, Ye Q, Tu J, Song Y. The location, histologic type, and stage of lung cancer are associated with bleeding during endobronchial biopsy. Cancer Manag Res. 2018;10:1251-7.

14. Harris K, Kebbe J, Modi K, Alraiyes AH, Kumar A, Attwood K, Dhillon SS. Aspirin use and the risk of bleeding complications after therapeutic bronchoscopy. Ther Adv Respir Dis. 2016;10:318-23.

15. Dzik WH. Predicting hemorrhage using preoperative coagulation screening assays. Curr Hematol Rep. 2004;3:324-30.

16. Zahreddine I, Atassi K, Fuhrman C. Impact of prior biological assessment of coagulation on the hemorrhagic risk of fiberoptic bronchoscopy. Rev Mal Respir. 2003;20:341-6. 
17. Darvall KA, Sam RC, Silverman SH, Bradbury AW, Adam DJ. Obesity and thrombosis. Eur J Vasc Endovasc Surg. 2007;33:223-33.

18. Kim CK, Cho DH, Lee KS, Lee DK, Park CW, Kim WG, Lee SJ, Ha KS, Goo Taeg $\mathrm{O}$, Kwon YG, et al. Ginseng berry extract prevents atherogenesis via antiinflammatory action by upregulating phase II gene expression. Evid Based Complement Alternat Med. 2012;490301:2012.

19. Eriksson M, Johnson O, Boman K, Hallmans G, Hellsten G, Nilsson TK, Soderberg S. Improved fibrinolytic activity during exercise may be an effect of the adipocyte-derived hormones leptin and adiponectin. Thromb Res. 2008;122:701-8,

20. Bansal N, Charlton-Menys V, Pemberton P, McElduff P, Oldroyd J, Vyas A, Koudsi A, Clayton PE, Cruickshank JK, Durrington PN. Adiponectin in umbilical cord blood is inversely related to low-density lipoprotein cholesterol but not ethnicity. J Clin Endocrinol Metab. 2006;91:2244-9.

21. Houde AA, Légaré C, Biron S, Lescelleur O, Biertho L, Marceau S, Tchernof A, Vohl MC, Hivert MF, Bouchard L. Leptin and adiponectin DNA methylation levels in adipose tissues and blood cells are associated with BMI, waist girth and LDL-cholesterol levels in severely obese men and women. BMC Med Genet. 2015;16:29.

22. Russo G, Pintaudi B, Giorda C, Lucisano G, Nicolucci A, Cristofaro MR, Suraci C, Mulas MF, Napoli A, Rossi MC, et al. Age- and gender-related differences in LDL-cholesterol management in outpatients with type 2 diabetes mellitus. Int J Endocrinol. 2015;2015:957105.

23. Carr IM, Koegelenberg CF, von Groote-Bidlingmaier F, Mowlana A, Silos K, Haverman T, Diacon AH, Bolliger CT. Blood loss during flexible bronchoscopy: a prospective observational study. Respiration. 2012;84:312-8.

\section{Publisher's Note}

Springer Nature remains neutral with regard to jurisdictional claims in published maps and institutional affiliations.

Ready to submit your research? Choose BMC and benefit from:

- fast, convenient online submission

- thorough peer review by experienced researchers in your field

- rapid publication on acceptance

- support for research data, including large and complex data types

- gold Open Access which fosters wider collaboration and increased citations

- maximum visibility for your research: over $100 \mathrm{M}$ website views per year

At $\mathrm{BMC}$, research is always in progress.

Learn more biomedcentral.com/submissions 